\title{
Performance Assessment of a Water Supply System under the Impact of Climate Change and Droughts: Case Study of the Washington Metropolitan Area
}

\author{
Roma Bhatkoti, Ph.D. ${ }^{1}$; Konstantinos Triantis, Ph.D. ${ }^{2}$; Glenn E. Moglen, Ph.D., P.E., F.ASCE ${ }^{3}$; \\ and Nasim S. Sabounchi ${ }^{4}$
}

\begin{abstract}
Fresh water demand is rising due to factors such as population growth, economic development, and land use changes. At the same time, climate change is rendering the water supply even more uncertain for the future. Due to recurring water restrictions and increasing water-related fees triggered by droughts and water shortages, there is a widespread, growing discomfort with respect to future water availability. Among key stakeholders and local policy makers, this has led to an increased interest in modeling the availability of water resources, with the aim of developing and implementing the appropriate water resource infrastructure and management strategies. This paper examines the Washington metropolitan area (WMA) water supply system and uses a system dynamics approach as a planning tool to make an exploratory assessment of the adequacy of the study area's water supply system to meet future water demand under the influence of substantial droughts and climate change. This assessment finds that the study area is self-sufficient under normal climate conditions during the entire planning horizon but that it will be strained under moderately severe droughts. On the basis of the temperature, streamflow and precipitation projections made by climate change models specific to the WMA region, climate change is expected to improve the water supply reliability. However, climate change has uncertainty associated with it. One of the four climate models for the Potomac River basin projects a decrease in the precipitation and streamflow, which may result in a reduction in the water supply and the system's reliability. Regulating the price and the system losses are valuable tools that can be leveraged. But these policy interventions require stakeholder participation (price regulation) and capital investments (reduction of distribution losses). Finally, system reliability can also be improved by increasing water supplies. DOI: 10.1061/(ASCE)IS.1943-555X.0000435. (C) 2018 American Society of Civil Engineers.
\end{abstract}

\section{Introduction and Background}

Fresh water demand is rising due to multiple factors such as population growth, economic development, and land use changes. Moreover, climate change is rendering water supply even more uncertain for the future (Evan and Davies 2011). Continued rising demand and climate uncertainty are not the only factors that affect future water availability; the third World Water Forum held in Kyoto concluded that water scarcity is often an outcome of mismanagement (WWF 2003). There is a growing discomfort regarding the recurring water restrictions and increasing water-related fees triggered by droughts and water shortages. This has led to an increased interest in modeling the availability of water in terms of supply and demand, with the aim of implementing the appropriate water resource management strategies (Evan and Davies 2011).

\footnotetext{
${ }^{1}$ Graduate Student, Dept. of Industrial and Systems Engineering, Virginia Tech, 7054 Haycock Rd., Falls Church, VA 22043-2311. Email: roma13@vt.edu

${ }^{2}$ Professor, Dept. of Industrial and Systems Engineering, Virginia Tech, 7054 Haycock Rd., Falls Church, VA 22043-2311 (corresponding author). Email: triantis@vt.edu

${ }^{3}$ Lab Director, USDA-ARS Hydrology and Remote Sensing Laboratory, Beltsville, MD 20705-2350. Email: Glenn.Moglen@ ars.usda.gov

${ }^{4}$ Assistant Professor, Dept. of Systems Science and Industrial Engineering, Binghamton Univ., 4400 Vestal Pkwy. East, Binghamton, NY 139026000. Email: sabounchi@binghamton.edu

Note. This manuscript was submitted on April 11, 2017; approved on March 23, 2018; published online on July 9, 2018. Discussion period open until December 9, 2018; separate discussions must be submitted for individual papers. This paper is part of the Journal of Infrastructure Systems, (C) ASCE, ISSN 1076-0342.
}

The WMA is the seventh largest US metropolitan area, and its population is expected to grow from its 2010 level by approximately $24 \%$ by 2040 (MWCOG 2009; ICPRB 2010). The WMA comprises 15 counties, six county-equivalent cities, and the District of Columbia. The main source of water in the WMA is the Potomac River. There are two additional reservoirs that are operated by regional water utilities. The Washington Suburban Sanitary Commission (WSSC) operates the Patuxent Reservoirs in the neighboring Patuxent River watershed, and the Fairfax County Water Authority (FCWA) operates a reservoir on the Occoquan River (Hagen and Steiner 1998). In addition, the WMA water suppliers collectively use the water stored in the Jennings Randolph (JRR) and Little Seneca Reservoirs (LSR) (USACE 1997; Hagen and Steiner 1999). Stagge and Moglen (2014) analyzed reservoir release decisions, using the WMA water supply as a case study. Their study depicts a map of the WMA region with its water resources.

This paper models a water supply and demand system for the WMA. [Note that this paper was adapted from the dissertation work of Dr. Bhatkoti (2016), with departures and enhancements.] This study aims to assess the adequacy of the current WMA water supply system to meet future water demand under the influence of substantial droughts and climate change and to create an interactive model to facilitate a dialogue among water managers, policy makers, and stakeholders. This paper also examines policy scenarios directed toward mitigating potential climate impacts on water availability rather than giving a precise numerical prediction of the volume of water stored in a reservoir, which is the purview of the hydrological models (Sušnik et al. 2012).

The water management system for the WMA, like many other public utilities, is reaching its maximum service potential in the 
face of rapid residential and commercial growth. For the present, episodic surges in demand, largely due to population and economic growth, have already demonstrated that they can exceed the current capacity, leading to off-strategy spending and inefficient workarounds (ICPRB 2010, 2013) in terms of planning, work hours, and coordination among various government agencies and water utilities. Droughts have already prompted withdrawals from the region's reserve water supplies, and associated water studies confirm that further stretching of reserve supplies is not a viable longer-term strategy (Van Dyne 2007).

Climate studies conducted for the entire mid-Atlantic region show an upward trend in temperature, precipitation, and streamflow (Neff et al. 2000). The United Nations Intergovernmental Panel on Climate Change attempted to evaluate and quantify the impact of human activity and its development on climate change. To do so, they developed a set of four socioeconomic scenarios. These scenarios allowed varying degrees of population change, development, technological improvements, and consumption for the next 100 years; they were labeled A1, A2, B1, and B2. These scenarios range from the most optimistic scenario, B1, in which the human population peaks around midcentury and declines thereafter, which shifts the focus of world economies from production to the service and information sectors, with significant reductions in material intensity and the introduction of clean and resource-efficient technologies, to the A2 scenario, in which the population continues to rise with regionally oriented economies, fossil fuel use continues unabated, and technological change is more fragmented and slower than in the other scenarios (Meehl et al. 2007; IPCC 2000, 2007). Najjar et al. (2009) applied the four scenarios to the general circulation models (GCMs) in order to get a detailed assessment of the impact of climate change on the Chesapeake Bay watershed and, more specifically, the Potomac River basin, which is within the Chesapeake Bay watershed. Table 1 presents the results of the study for the Potomac watershed.

The four climate change scenarios, as applied to the Chesapeake Bay watershed GCMs, suggest an increase in the annual mean temperature by $1.25^{\circ} \mathrm{C}$ by 2030 . The mean annual precipitation is expected to increase by $4 \%$ by 2030 (Najjar et al. 2009). Similarly, the streamflow is expected to increase by $2 \%$. Predictions about streamflow in the Potomac watershed have much greater variability than predictions about the temperature or precipitation (Neff et al. 2000; Wolock and McCabe 1999; Meehl et al. 2007; Najjar et al. 2009). Streamflow prediction is more challenging than temperature and precipitation prediction because it requires assessing water balance equations that include the temperature, precipitation and groundwater levels.

Although the high uncertainty and variability in climate change models pose problems for policy makers, the information from these models can be incorporated into various plausible scenarios for simulation studies to assess system performance under the influence of climate change. In this study, we used temperature, precipitation, and streamflow range projections made by Neff et al. (2000) and Najjar et al. (2009).

Table 1. Climate change impacts in the Potomac River basin

\begin{tabular}{llc}
\hline & \multicolumn{2}{c}{ Year 2030 } \\
\cline { 2 - 3 } Parameter & Mean & Range \\
\hline Temperature $\left({ }^{\circ} \mathrm{C}\right)$ & +1.25 & +1 to +1.5 \\
Precipitation $(\%)$ & +4 & -1 to +8 \\
Streamflow $(\%)$ & +2 & -2 to +6 \\
\hline
\end{tabular}

Source: Adapted from Najjar et al. (2009).
Water resources are modeled at many scales. Various global water models and water scarcity studies have been conducted (Saysel et al. 2000; Alcamo and Henrichs 2002; Chung et al. 2008; Kojiri et al. 2008). Hanasaki et al. (2013a, b) in their two-part study assessed water scarcity using global hydrological models and the latest global change scenarios. They attributed global water scarcity mostly to population and economic growth and partly to global warming. Wada et al. (2010) used a global hydrological model to show how an increase in groundwater abstraction led to global sea-level rise. Hejazi et al. (2014), similarly to Meadows et al. (1972), used a global scale, technologically detailed model to make water scarcity projections for world regions. They projected water scarcity to increase for some regions such as the Middle East and India, and to improve for certain other regions such as Canada and the US.

Local models have also been developed to facilitate decision making by local and regional governments, because local governments have the authority to make water withdrawal, distribution, and conservation related policies (Langsdale et al. 2007; Madani and Mariño 2009; Stave 2003). In a regional study, Dawadi and Ahmad (2013) applied a system dynamics (SD) methodology to study the impact of various policies such as water pricing and conservation. The model, based in Las Vegas, Nevada, included the effect of climate change and population growth on water demand but did not take into account the impact of public perception on population growth. Qaiser et al. (2013) also used a SD modeling approach to study water demand and supply in the Las Vegas Valley. The effect of water conservation and use of recycled water with different population growth rates was simulated. The population growth rate was modeled as an exogenous factor without capturing public perception and the response to water conservation policies. Hassanzadeh et al. (2014) similarly develop a SD model for water resource management in Canada. The model focuses on agricultural water use and incorporates hydropower, agriculture, and municipal demand. Van Emmerik et al. (2014) developed a SD model to capture the complex interactions between human and hydrological systems over the past century in the Murrumbidgee River Basin in Australia. Climate and socioeconomic drivers were captured with exogenous factors in the model. The model replicated the historical patterns of population growth, technological adoption, and surface water use for agriculture and food production in the region of study. The boundary and time horizon of this modeling study was different from our approach. Wang and Davies (2015) used a SD approach to develop a simulation tool and experimental environment for testing drought management policies. The tool was used at various Canadian Agriculture and Agrifood invitational drought tournament events by different teams. The model results generated by participants demonstrated the effectiveness of the selected policies to mitigate drought conditions. The study confirmed that these simulation platforms assist in better understanding the complexity of water resource management. Yang et al. (2015) also developed a SD model to predict the potential maximum socioeconomic and population growth within an area with a natural water resource capacity. The model was simulated for Tieling city in China, and the results demonstrated that such modeling is useful for assessing sustainable economic development.

Different methodologies have been used to model the processes responsible for the spatial and temporal distribution of water resources at a local level, including a multiagent simulation approach to represent the local water use of the Jaguaribe basin in northeastern Brazil (Van Oel et al. 2010). Various water supply system managers have used a combination of optimization and simulation techniques for improving water resource efficiency and effective reservoir management (Sheer 1977; Palmer et al. 1982, 1979). Specialized modeling tools have been developed to simulate 
water supply systems (Ocanas and Mays 1981; Huang and Loucks 2000; Ejeta et al. 2004; Cohen et al. 2004). These tools are often specific to a system and difficult to adapt to other systems. Furthermore, some lack a user-friendly interface (Chung et al. 2008).

Modeling the water supply and demand system is challenging because of its complexity in terms of the number of subsystems involved and their interactions. The subsystems include the reservoir, the distribution, the environment policy, and the water demand systems. This complexity makes it difficult to develop a comprehensive mitigation and adaptation strategy that appeals to all stakeholders and policy makers and to educate the public about the elements that may cause a water supply and demand system to lose reliability due to droughts, population increase, aging water infrastructure, and climate change. Therefore, simulation and modeling approaches that can represent a water supply and demand system with its components and that can demonstrate the effects of management policy interventions can be extremely valuable (Chung et al. 2008).

A system dynamics methodology is used for this research to build and assess quantitatively the impact of climate change and policy interventions. The SD model was developed for the purposes of (1) quantitatively assessing the adequacy of current water resources available to the region, to meet future water demand; (2) analyzing the impact of substantial droughts and low flows on water availability; and (3) assessing the sensitivity of the region's water supply system under various climate change scenarios and policy intervention scenarios. The SD approach allows one to (1) isolate the key causal relationships among the system elements; and (2) graphically represent the constellation of subsystems for the lay policy maker. Moreover, the SD assumes a continuous process that allows an examination of the effects of multiyear droughts on different reservoirs.

The main advantage of our approach is to provide an integrated assessment of a water supply and demand system. The generality of system dynamics simulation allows the representation of multiple resources and stakeholders and an investigation of the feedback effects of various water resource policies (Davies and Simonovic 2011). Policy makers and stakeholders are able to understand the relationships that constitute the structure of the model (Chung et al. 2008; Sterman 2000). SD modeling has the ability to capture time delays that influence the behavior of the system (Sterman 2000). For example, our model includes a major delay between the time

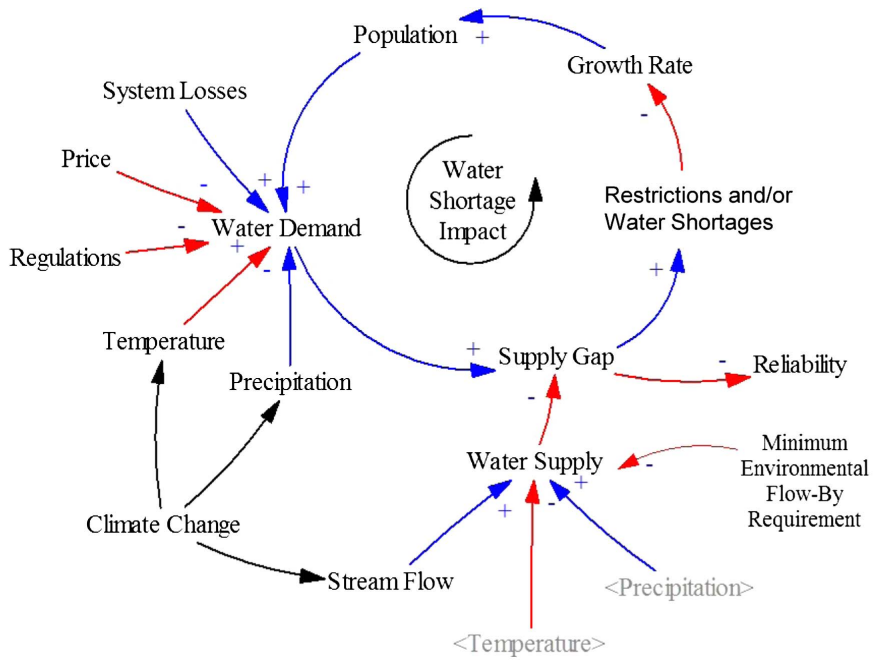

(a) of the imposition of water use restrictions and the time it impacts the population growth rate of the region. Our approach captures important feedback structures that govern the dynamics of the water system, such as the feedback from water shortage and the water use restrictions that cause discomfort to people, which has a negative impact on the region's population growth rate. Our framework makes it possible to develop models that connect various subsystems to formulate the structure of the whole system. In this study, the water supply and demand model is composed of two major subsystems, the water demand and the water supply. Our approach has a very user-friendly graphical interface that enables multiple stakeholders (water managers, civil engineers, public policy makers, and environmentalists) to visualize the system with all its components and linkages (Langsdale et al. 2007; Madani and Mariño 2009; Stave 2003). In our study, we graphically represent the WMA water supply and demand system with its major components and connections. This graphical representation facilitates communication and collaboration among the different parties of interest and facilitates our modeling goals.

\section{Methodology and Model Development}

In the WMA water supply and demand model developed in this paper, socioeconomic factors such as population, price, regulation policies, and weather affect the total water demand. Temperature and precipitation are included to impart seasonality to the average annual water demand. The water supply is taken from water reservoirs and rivers. The difference between water supply and water demand is termed a supply gap that determines the reliability of the system. The supply gap results in restrictions and/or water shortages for the region. Water shortages and restrictions lead to resident discomfort, causing the population growth rate and population to decrease. The population in turn affects the total water demand, thus closing the loop [Fig. 1(a)]. Fig. 1(b) shows all the water demand and supply components.

\section{Water Supply Submodel}

In the model the water supply consists of the Potomac River system and two separate reservoirs operated by the WMA utilities, the Patuxent reservoir and the Occoquan reservoir. All utilities collaborate

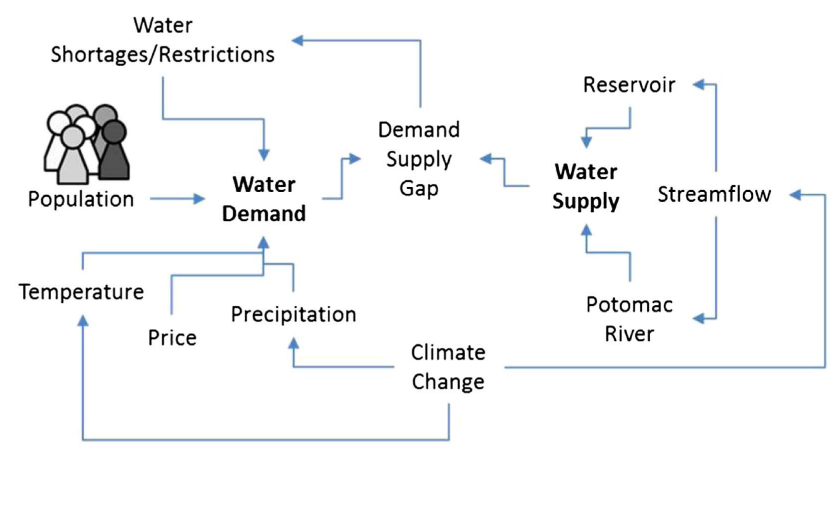

(b)

Fig. 1. (a) Causal loop diagram of the WMA; and (b) water demand and supply components. 
to provide water storage in the Jennings Randolph reservoir and the Little Seneca reservoir (ICPRB 2010). The average annual streamflow for the Potomac River is around 26.4 million $\mathrm{m}^{3} /$ day. For much of the year, water supply withdrawals from the Potomac remain a small fraction of the river's flow, because the average summer demand for water by the WMA suppliers is approximately 1.9 million $\mathrm{m}^{3}$ /day (ICPRB 2010). This may give a false sense of water availability for the region. The critical aspect here is the streamflow variability. The lowest observed flow in the Potomac was 1.3 million $\mathrm{m}^{3} /$ day during the summer of 1966 . Due to the large flow variability, the water supply system that relies solely on the Potomac flow may not meet the daily demand targets. Additionally, the total available Potomac water is further constrained by the minimum environmental flow-by requirements to protect aquatic life forms (Kiang and Hagen 2003). Changes to the minimum flowby requirements will influence the water availability in the system.

\section{Water Demand Submodel}

The model estimates the water demand per person (represented as per capita water demand) as a function of the price and the price elasticity of demand (Fig. 2). Because price changes do not immediately lead to changes in the water demand per person, the model first calculates the projected per capita water demand due to price change. It then updates the water demand per person by adjusting its difference with the projected water demand represented by the gap with the projected water demand. This gap with the projected water demand is adjusted with a time delay represented by the time to change water demand

\section{Projected per capita water demand due to price change}

$$
=\text { Reference water use } * \text { Price } \text { Elasticity of price }^{\text {El }}
$$

where Price is in dollars/cubic meter; Elasticity of price is dimensionless; and Projected per capita water demand due to price change and Reference water use are in cubic meters/day/person.

For the WMA, the per capita water demand is impacted by the Energy Policy Act (EPA) of 1992 (Vickers 1993). The EPA of 1992 calls for the use of more efficient plumbing fixtures for both commercial and residential use. This policy aims to reduce water consumption solely by putting low-flow restrictions on the types of appliances installed in homes and commercial establishments. The model differentiates the demand with EPA and the demand without EPA. The WMA population is divided into two stocks: the population (Stock 1) with EPA, who live in households that have EPA-regulated low-flow appliances; and the population (Stock 2) without EPA, who live in households that do not have EPA-regulated low-flow appliances. The growth rates of the two population stocks are proportional to their volumes as calculated in Eqs. (2) and (3). The total water demand is then the sum of the product of both stocks and their respective flows

$$
\begin{aligned}
& \text { Growth rate (Population with EPA) } \\
& =\text { Growth rate } *\left(\frac{\text { Population }(\text { Stock } 1) \text { with EPA }}{\text { Total population }}\right)
\end{aligned}
$$

Total water demand $=$ Population $($ Stock1) with EPA

$$
\begin{aligned}
& * \text { Per capita water demand of people affected } \\
& \text { by EPA + Population (Stock2) with out EPA } \\
& * \text { Per capita water demand of people affected } \\
& \text { by EPA }
\end{aligned}
$$

The effect of weather on water demand, hereafter referred to as seasonality, is incorporated by including impact of the average

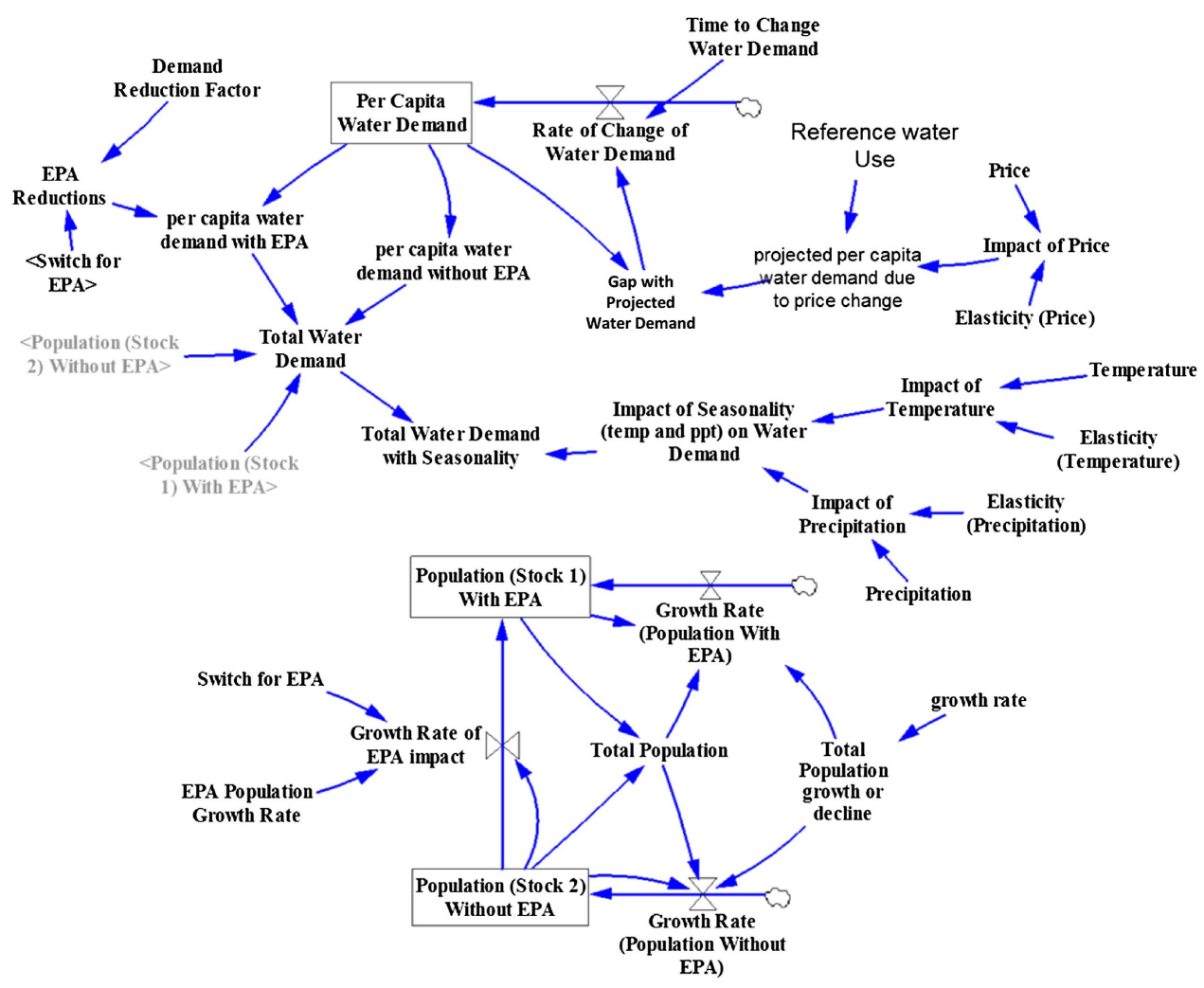

Fig. 2. Demand side of the model. 
extreme maximum temperature (degrees Celsius/month) and the total monthly precipitation (millimeters/month) [Eq. (4)]. Eqs. (1) and (4) are popularly used in water demand estimation. This assumes the elasticity to be constant over the range of values for the independent variables that determine water use (Schleich and Hillenbrand 2009; Arbués et al. 2000; Dandy et al. 1997; Williams 1985). We estimate the elasticity of price (dimensionless), the EPA population growth rate (persons/month), the reference water use (cubic meters/day/person), the elasticity of temperature, the elasticity of precipitation, the total water demand, and the total water demand with seasonality (cubic meters/day) through the calibration of our model, whereas the remaining parameters such as the demand reduction factor due to EPA compliance (dimensionless) are available in the literature (Vickers 1993)

$$
\begin{aligned}
& \text { Total water demand with seasonality }\left(D_{i}\right) \\
& =\text { Total water demand } \\
& \quad * \text { Average extreme maximum temperature }{ }^{\text {Elasticity of temperature }} \\
& \quad * \text { Total monthly precipitation }
\end{aligned}
$$

Water in the Potomac River is sufficient to satisfy the daily water needs of the WMA customers except during prolonged drought conditions. The Potomac River flows are augmented by releases from the JRR during such times. The system, which has existed since the 1980s, has thus far had three summers when such releases have been made: 1999, 2002, and 2010 (Hagen and Kiang 2002; Ahmed et al. 2011; Bencala et al. 2013). The historical instances were used as a check to demonstrate that our model matched the timing of the releases from the JRR (Fig. 3).

\section{Consumer Discomfort-Population Growth Relationship}

Water releases from the JRR are a cause of concern for the WMA region because they deplete the primary savings account of the region, the JRR (ICPRB 2010). Moreover, the JRR releases are often accompanied by water use restrictions (LeDuc and Wilson 1999) such as regulations on lawn watering, swimming pool operation, washing cars, and hosing down driveways (LeDuc and Wilson 1999). Mirchi (2013) estimated that water quality problems might decrease the attractiveness of the area, causing a population decrease.

Meadows et al. (1972) demonstrated how a region's resources (food) limit the population growth rate. In a similar fashion, we constructed a scenario in which we assume that population growth will

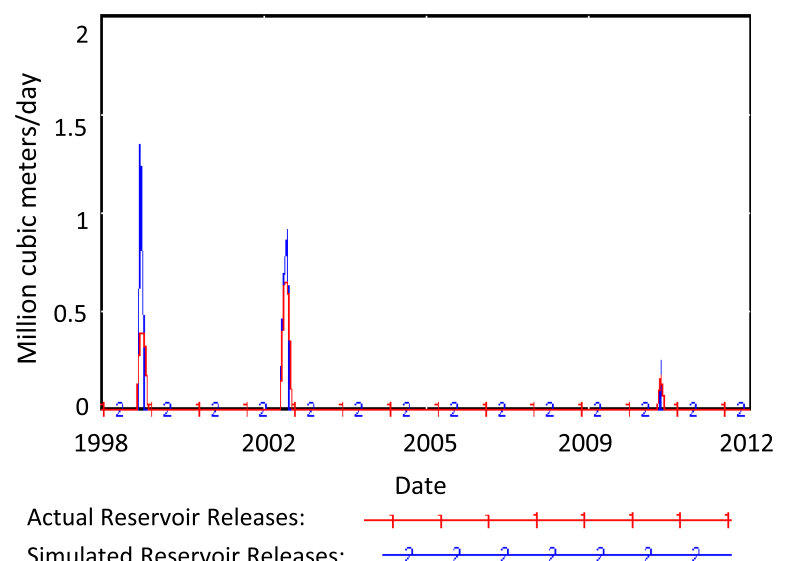

Fig. 3. Instances requiring releases from the reservoir. be affected by the unavailability of water resources and the discomfort caused by water use restrictions (Fig. 4). To account for the impact of water shortage and water restrictions on the water supply and demand system, we define Impactl as the discomfort caused when the region is able to fulfill demand but uses its savings account to make withdrawals accompanied by water use restrictions that are enforced on people. Impact 2 is defined as the discomfort caused by the water shortage when the region fails to meet demand and there is not enough water supply to fulfill demand (Fig. 4). Impactl is a function of the perceived discomfort (dimensionless) caused by water use restrictions [Eq. (5)], and Impact2 is a function of perceived discomfort caused by water shortage [Eq. (6)]

$$
\begin{aligned}
& \text { Impact } 1=f_{1}(\text { perceived_discomfort } R) \\
& \text { Impact } 2=f_{2}(\text { perceived_discomfort_S })
\end{aligned}
$$

We assume that both functions $f_{1}$ and $f_{2}$ have the same shape and behavior (Fig. 5). When there are no restrictions and water shortages then the perceived_discomfort_R and perceived_discomfort_S are both 0 , and Impact1 and Impact2 are equal to 1 (point A). As the perceived discomfort increases, its impact on growth rate becomes negative. In Fig. 5, the horizontal line represents both perceptions, and we assume the same functional form that captures the impact of these perceptions. Impact1 and Impact 2 contribute to Eq. (7) to determine the population growth rate.

The purpose of this paper is to provide a simulation framework that can be used by policy makers to find effective water management strategies in response to predicted population growth in the region. The simulation model developed in this paper can be used to explore relationships between water availability and future population growth and decline in the region. As discussed previously, the WMA region has not experienced a regionwide water use restriction. We could not find any other documented data that depict the extreme scenario of water restrictions/shortage impact on the population growth/migration. Because data are not available on the impact of water restrictions on population growth, in our model we have made an assumption that when the perceived discomfort increases, then population growth declines, and when perceived discomfort reaches $20 \%$, then the population starts to move out of the region. The curve that depicts the relationship between the impact of public perception on migration (Fig. 5) is based solely on our assumptions. One can further explore variations of this relationship and perform sensitivity analysis within the simulation model. There is no limitation on performing such analysis, but considering that there are no historical trends to compare and contrast with the sensitivity analysis results, we do not include this analysis in this paper. We made reasonable assumptions about the relationship between public perception and migration. One could change the functional form of this relationship in future iterations of the model. The point is that the model provides a framework in which future changes can be incorporated for a different set of functional forms associated with the relationship between public perception and migration.

We define the net fraction population growth rate $(n g r)$ of the region by multiplying the base fraction growth rate (bgr) that is the population growth rate of the WMA region without taking into account the water shortages estimated by the Metropolitan Washington Council of Governments forecast (MWCOG 2009; ICPRB 2010), and the weighted average of Impactl and Impact2 [Eqs. (7) and (8)]. The weights can vary depending on the severity of one impact in comparison with the other. It is intuitive that people may be more stressed if the region suffers water shortage as opposed to following restrictions and thus assume $w_{2}$ to be greater than $w_{1}$ (we assume $w_{1}=0.25$ and $w_{2}=0.75$ ). When 


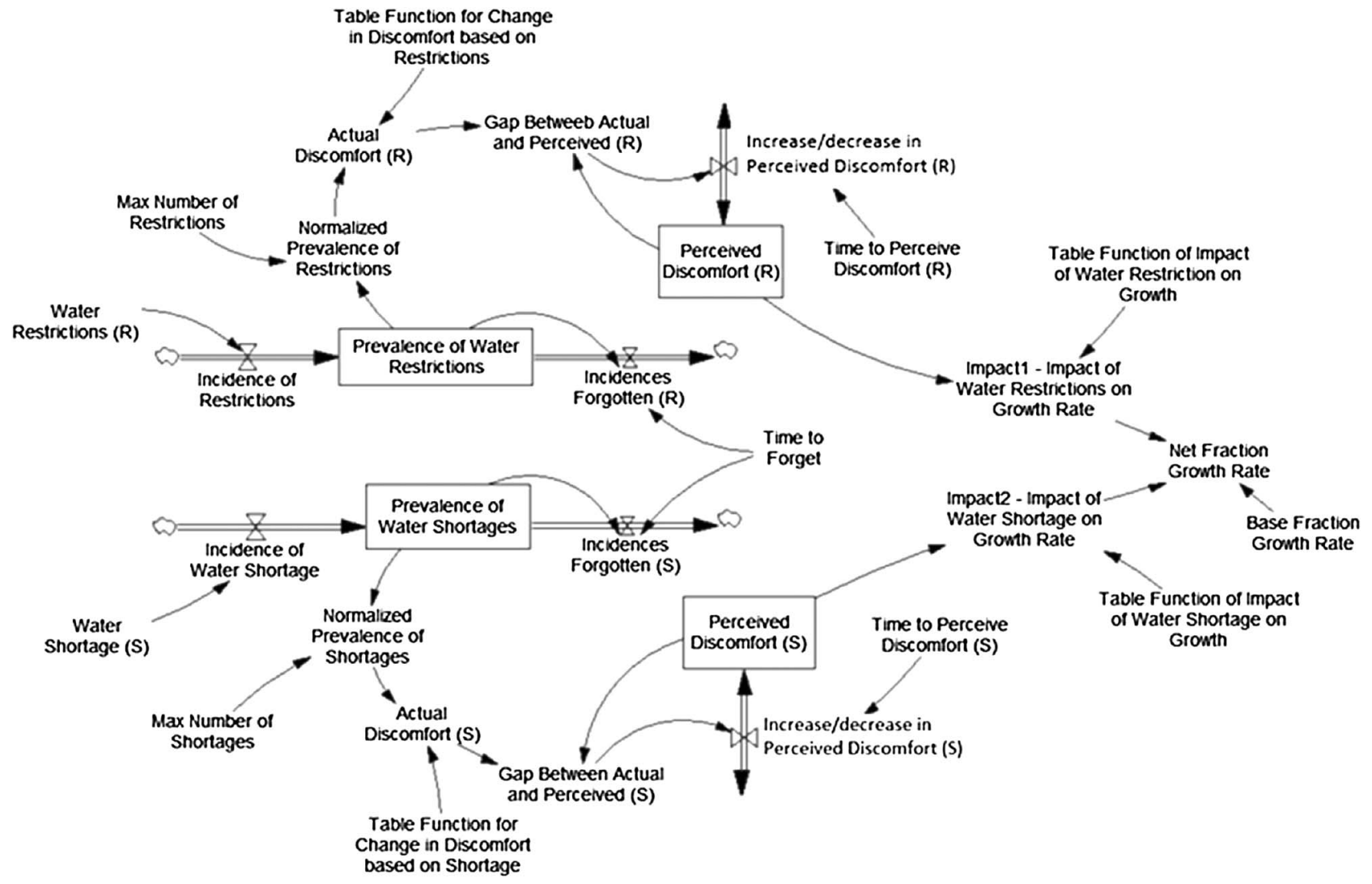

Fig. 4. Closing the loop, and connecting demand and supply with population growth.

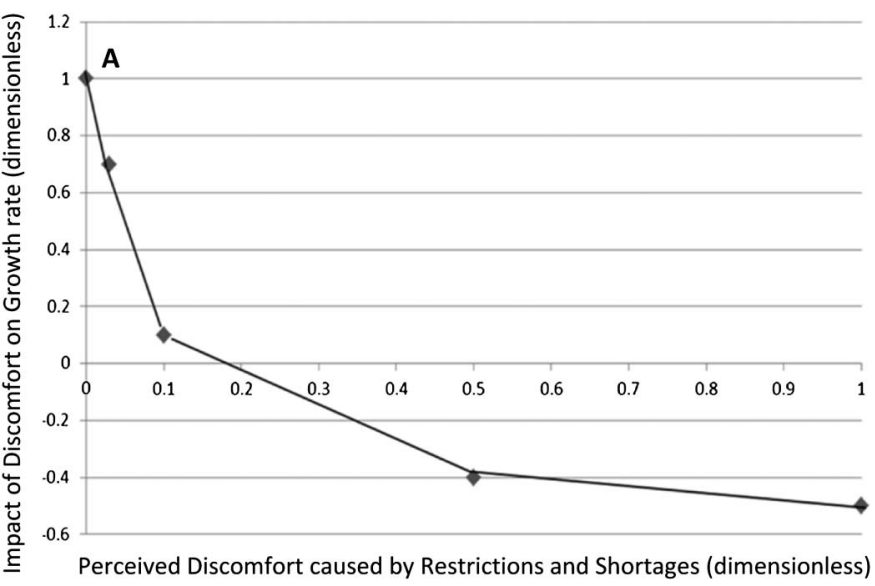

Fig. 5. Connecting perceived discomfort to population growth rate.

the discomfort and water shortage increase (for example, perceived_ discomfort_S and perceived_discomfort_R $=1$ ), the stress becomes negative, thus making the net growth rate negative

$$
\begin{gathered}
n g r=\operatorname{bgr} *\left(w_{1} * \operatorname{Impact} 1+w_{2} * \operatorname{Impact} 2\right) \\
w_{1}+w_{2}=1
\end{gathered}
$$

Both the perceived discomfort variables caused by water use restrictions [Eq. (9)] and the water shortage do not change instantaneously but build over time. Individuals are assumed to take time to gather information and to form beliefs and judgments (Sterman 2000). Thus, there is a time delay from a change in the physical world to the time people begin to realize these changes. Exponential smoothing or adaptive expectations are most widely used to model such information delays involving humans, meaning that human perception gradually adjusts to the actual value of the variable (Sterman 2000)

$$
\begin{aligned}
& \text { perceived_discomfort }(t) \\
& =\text { perceived_discomfort }(0) \\
& \quad+\int_{0}^{t}(\text { Change in perceived discomfort }) d t
\end{aligned}
$$

$$
\begin{aligned}
& \text { Change in perceived discomfort } \\
& =\frac{\text { Actual discomfort }(t)-\text { Perceived discomfort }(t)}{\text { Time to perceive discomfort }}
\end{aligned}
$$

In Eq. (9) the perceived discomfort at time $t$ is equal to the sum of the perceived discomfort at the start of simulation $\left(t_{0}\right)$ and the integral of the rate of change of the perceived discomfort for the time period between $t_{0}$ and $t$. Also the rate of change of the perceived discomfort is defined in Eq. (10), which is equal to the difference between the actual discomfort and the perceived discomfort at time $t$ divided by the time it takes for the perceived discomfort to adjust to the actual discomfort level.

In the model, we define the time to perceive discomfort (in months) as the time required by the individuals to perceive water resource scarcity. Because the WMA had never experienced any regionwide imposition of water use restrictions, the model could not be calibrated to calculate this time delay parameter. However, there are studies that calibrate similar parameters such as the resource shortage perception delay (Meadows et al. 1972), energy shortage 


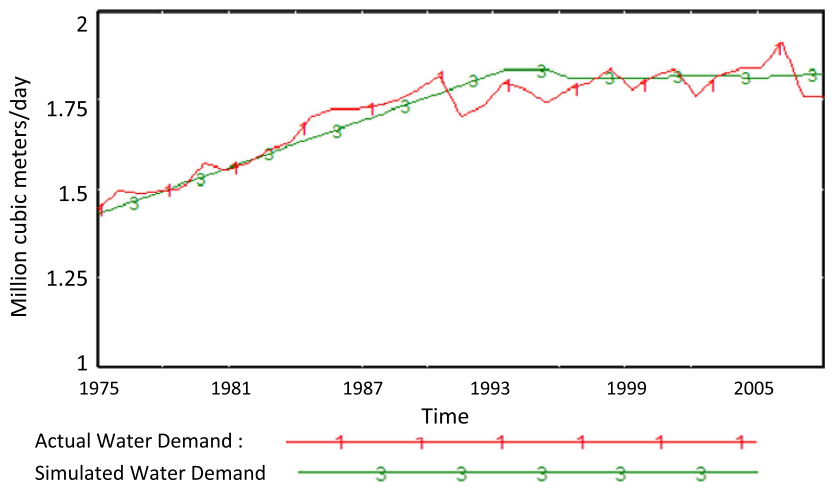

Fig. 6. Actual versus simulated total water demand in the WMA from 1975 to 2008.

perception (Wright 1975), feedback delay (Honda et al. 2013), perception delay (Juhn et al. 1999; Mehmet and Yasarcan 2015; Dutta et al. 2014), and response delay (Meadows 2008). In our study we defined the time to perceive discomfort to be 24 months, based on the resource shortage perception delay used by Meadows et al. (1972).

To conclude, the difference between water demand $\left(D_{i}\right)$ and water supply determines the supply gap that leads to water shortages. Water shortages, in turn, impact the growth rate (with some delay), which determines the total population of the region and hence impacts the water demand $\left(D_{i}\right)$ for the region (closing the loop, as shown in Fig. 1).

\section{Simulation Results and Discussion}

Some model parameters, including demand elasticities, EPA population growth rate, and reference water use, do not have a given value in the literature. We calibrate these parameters by comparing the simulated water demand (cubic meters/day) with the actual water demand (cubic meters/day) values (ICPRB 2010) for the WMA region. During calibration, we define the objective function as the sum of the difference between the actual water demand and its simulated value, multiplied by a squared weight $\left(w^{2}\right)$ [Eq. (11]) (Sabounchi et al. 2014; Vensim 2010). The weight is the inverse of the standard deviation of the error term (the difference between the actual and simulated values). The objective function is minimized over three or more iterations of calibration, and the estimated parameters converge to their maximum likelihood estimator (Dogan 2007). Fig. 6 shows the simulated and actual water demand curves. We assessed the calibrated parameter values and found them consistent with relevant descriptive and numerical system knowledge. Table 2 provides the calibrated parameter values

$$
\begin{aligned}
& \operatorname{Minimize}\left(\int _ { t = \mathrm { Jan } , 1 9 7 5 } ^ { t = \mathrm { Dec } , 2 0 0 8 } \left(\left(w _ { t } \left(\text { Water demand historical }_{t}-\text { Water demandsimulated }_{t}\right.\right.\right.\right. \\
& * \text { (Elasticity ( Price), EPA population growth rate, Reference water use, Elasticity (Precipitation), Elasticity (Temperature), }
\end{aligned}
$$

Demand reduction factor, Growth rate, Minimum flow by requirement, Time to perceive discomfort, Reduction due

$$
\text { to emergency restrictions, Reduction due to mandatory restrictions, due to voluntary restrictions)) } \left.)^{2} d t\right) \text { ) }
$$

We used the calibrated model to analyze the impact of historical droughts and low flows on water availability and to examine the impact of climate change and policy variables on system performance. For this purpose, we simulated the model for a period of 24 years from 2016 to 2040 under normal and drought scenarios. A simulation period of 20 to 30 years is a reasonable forecast horizon for water supply reliability studies (ICPRB 2010; Langsdale et al.

Table 2. Key model parameters

\begin{tabular}{lc}
\hline Parameter & Value \\
\hline Elasticity of price & -0.037 \\
EPA population growth rate (persons/month) & 0.0025 \\
Reference water use $\left(\mathrm{m}^{3} /\right.$ day) & 0.5 \\
Elasticity of precipitation & -0.115 \\
Elasticity of temperature & 0.15 \\
Demand reduction factor & 0.63 \\
Growth rate (persons/month) & 3,200 \\
Minimum flow-by requirement (million $\mathrm{m}^{3} /$ day) & 0.9 \\
Time to perceive discomfort (months) & 24 \\
Reduction due to emergency restrictions & 0.85 \\
Reduction due to mandatory restrictions & 0.9 \\
Reduction due to voluntary restrictions & 0.95 \\
\hline
\end{tabular}

2007; Madani and Mariño 2009; Stave 2003). Moreover, agreements signed by the WMA's water suppliers and the Metropolitan Washington Council of Governments (MWCOG), such as the Water Supply Coordination Agreement (WSCA) and the Low Flow Allocation Agreement (LFAA) also call for periodic water demand and resource availability studies with a 20- to 30-year time horizon.

In order to gauge whether the water supply and demand system is performing as intended, it is necessary to assess its performance under a wide range of conditions and scenarios expected during the operating life. We used the volumetric reliability $\left(R_{v}\right)$ to evaluate the water supply and demand system performance under normal and drought scenarios. This metric was calculated on the basis of the proportion of total water demand that could not be met during the simulation period (McMahon et al. 2006). For this purpose, we found the difference between the water demand $\left(D_{i}\right)$ and water supply $\left(D_{i}^{\prime}\right)$ for each simulated period $(i)$ in which the water supply system was not able to meet the demand. In other words, $D_{i}-D_{i}^{\prime}$ would be treated as 0 for the periods that demand is met. The ratio of total unmet demand over the total demand during $N$ simulation periods defines the volumetric unreliability of the system. Therefore, its difference from 1 measures volumetric reliability 
$\operatorname{Reliability~}_{v}\left(R_{v}\right)=1-\frac{\sum_{i=1}^{N}\left(D_{i}-D_{i}^{\prime}\right)}{\sum_{i=1}^{N} D_{i}} ; \quad 0<$ Reliability $_{v} \leq 1$

\section{Drought Scenario Analysis}

Next, in order to examine the effect of prolonged droughts on WMA water availability, five drought scenarios were imposed on the simulation model of the WMA water supply and demand. We used the historical instances of droughts and their corresponding data for the temperature, precipitation, and streamflow to impose future drought scenarios on the water supply and demand system during the simulation period of 2031 to 2040 . For instance, the historical data for temperature, precipitation and streamflow for the drought year of 1999 [Potomac streamflow data is provided online (USGS 2015)] were imposed on the system to create future drought scenarios; data for 2004 were used to create future nondrought or normal scenarios.

A moderately severe drought scenario (ICPRB defines the droughts of 1999 and 2000 as moderate droughts) X (DRx) was created by imposing the temperature, precipitation and streamflow data of 1999 at intervals of $x(x=1,2,3,4$, and 5) years (Table 3). Such scenarios were created to examine the reliability of the water supply system under extreme conditions of decade-long droughts, similar those occurring in the western US (Rogers 2014).

The simulation was performed for droughts (DR $x$ ) and for normal (NS) scenarios. Fig. 7 shows the impact of the drought scenarios in the region. The spikes in the graphs represent the component of water demand (in million cubic meters per day) that was not fulfilled by the current water supplies. The WMA supplies

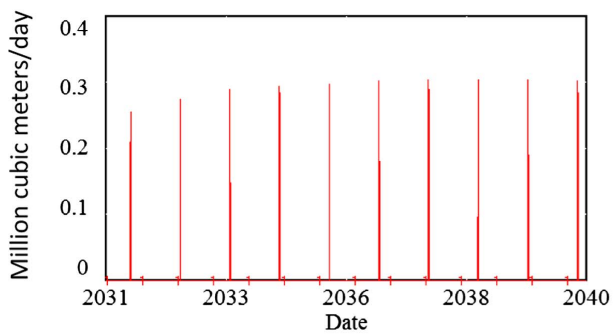

(a) Unfulfilled Demand : DR1 $+, 1,+, 1$,

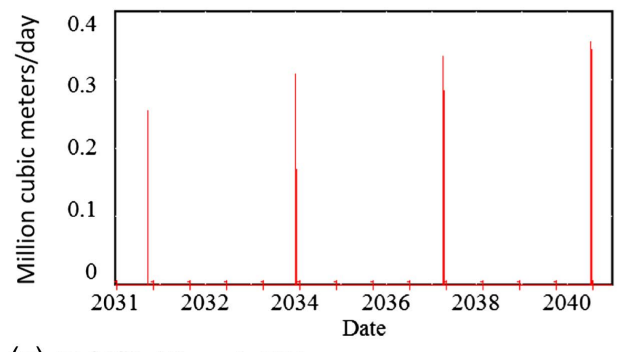

(c) Unfulfilled Demand : DR3

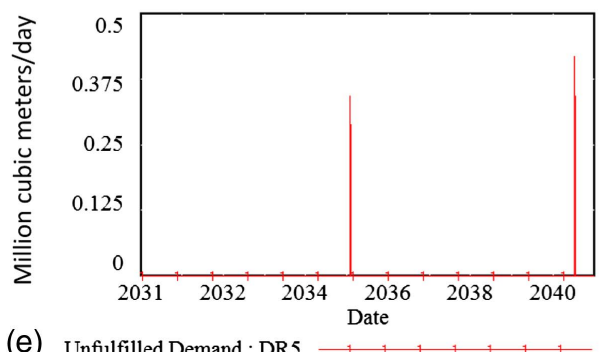

Table 3. Drought scenarios

\begin{tabular}{lcccccccccc}
\hline Drought & \multicolumn{10}{c}{ Year } \\
\cline { 2 - 9 } scenarios & 2031 & 2032 & 2033 & 2034 & 2035 & 2036 & 2037 & 2038 & 2039 & 2040 \\
\hline NS & - & - & - & - & - & - & - & - & - & - \\
DR1 & D & D & D & D & D & D & D & D & D & D \\
DR2 & - & D & - & D & - & D & - & D & - & D \\
DR3 & D & - & - & D & - & - & D & - & - & D \\
DR4 & - & D & - & - & - & D & - & - & - & D \\
DR5 & - & - & - & - & D & - & - & - & - & D \\
\hline
\end{tabular}

Note: Cells with D represent drought, and empty cells represent no drought. For example, scenario DR1 indicates that WMA is faced with a moderately severe drought every year from 2031 to 2040.

would not be sufficient to meet demand if a moderately severe drought occurred on the system every $x$ year $(x=1,2,3,4$, and 5); Figs. 7(a-e) show the graphs for the drought scenarios DR1-DR5, respectively. The model also predicts that the region has sufficient water resources to fulfill the demand for the entire simulation period (2016-2040) under normal scenarios; Fig. 7(f) shows the graph for the normal scenario (NS).

The water availability analysis for the region shows that the WMA region would start experiencing water shortfall in 2028 (Fig. 8). Fig. 8(a) shows that in 2028, there will be few days when the WMA supplies will not be sufficient to fulfill demand. Fig. 8(b) shows the cause of the shortfall. Fig. 8(b) shows that not only will the WMA region's water demand be more than the Potomac streamflow, but that the available reservoir volume will drop to near 0 (the inset shows the reservoir volume).

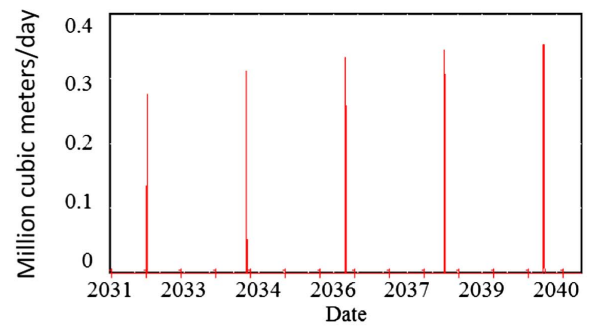

(b) Unfulfilled Demand : DR

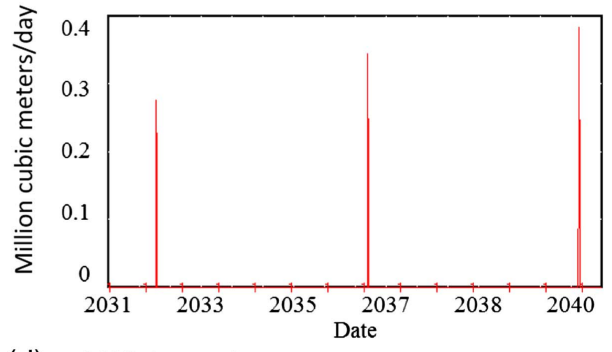

(d) Unfulfilled Demand : DR4

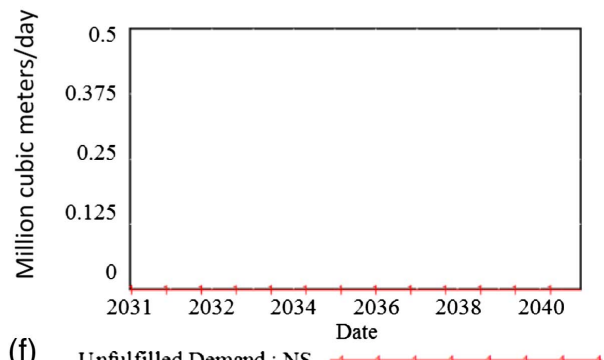

Fig. 7. Water unavailability under normal scenario (NS) and drought scenarios (DRx): (a) DR1; (b) DR2; (c) DR3; (d) DR4; (e) DR5; and (f) NS. 


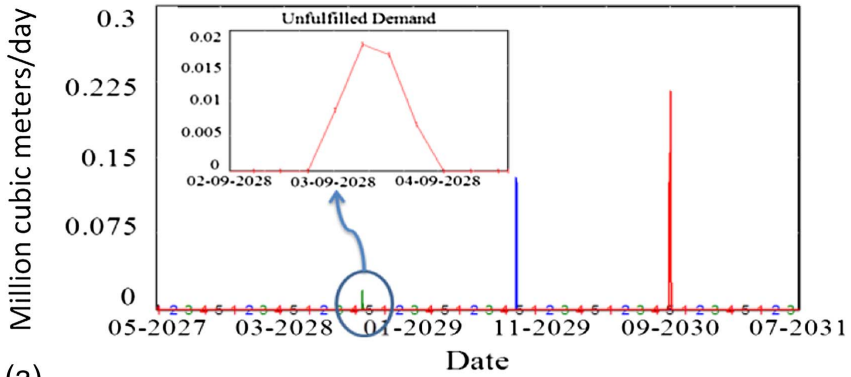

(a)
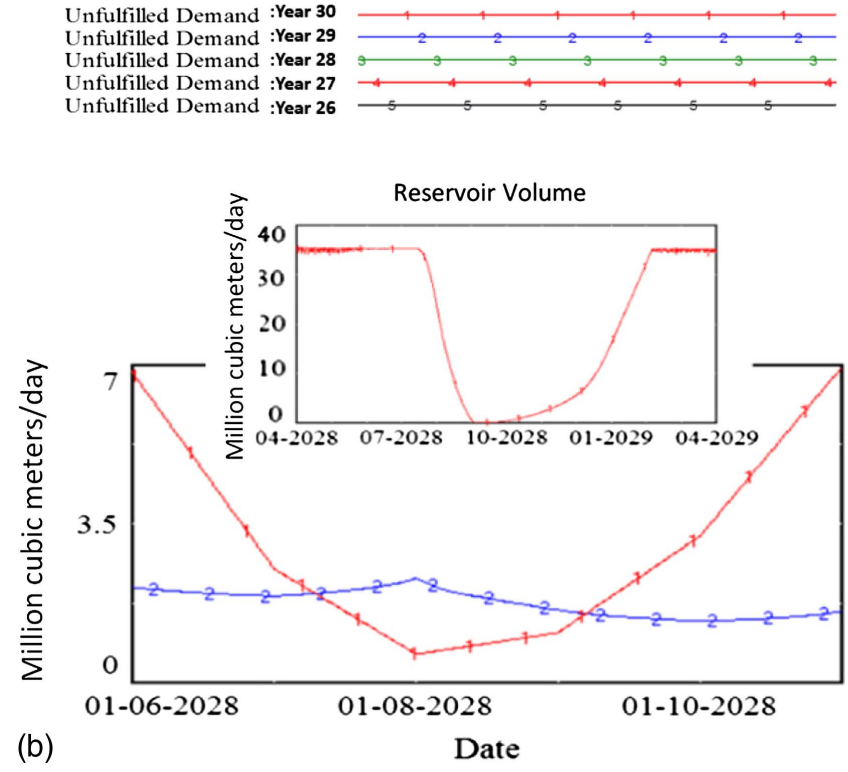

Potomac Streamflow : Year 28

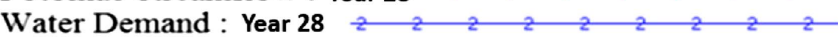

Fig. 8. Water availability in (a) May 2027-July 2031; and (b) the year 2028 under moderately severe drought.

An interesting observation is that the reliability of the system for the 10-year simulation period (2031-2040) dropped as the frequency of drought decreased from every year (DR1) to every fifth year (DR5). Volumetric reliability dropped from 88 to $84 \%$ from drought scenario 1 to drought scenario 5. The reason for this drop lies in the feedback that connects water unavailability and people's discomfort that impacts the population growth rate. Drought scenario DR1 is the harshest because it imposes drought on the system every year from 2031 to 2040; it reduces the population growth rate of the region [Fig. 9(a)]. This causes the population to grow at a slower rate [Fig. 9(b)]. Therefore, the total water demand is less under DR1 scenario than in $\operatorname{DR} x(x=2,3,4$, and 5).

\section{Climate Change Scenario Analysis}

We used the simulation model to analyze how the WMA water supply and demand system would perform under climate change scenarios. Climate change affects the water supply and demand system through temperature, precipitation and streamflow. Temperature influences water use and reservoir volume through evaporation, thus affecting both water demand and water supply. Similarly, precipitation impacts both supply and demand by affecting the water demand and reservoir volume through precipitation directly over the area of the reservoir. Last, streamflow affects only the water supply. The impact of climate on precipitation varies from region to region. Climate studies conducted for the entire mid-Atlantic
Total Population growth or decline

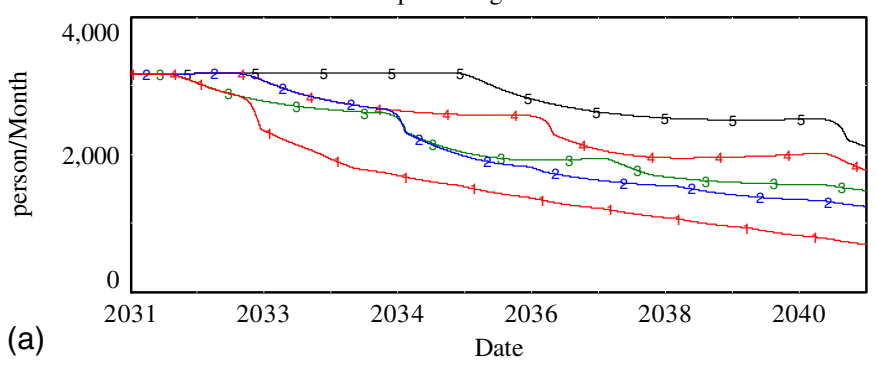

Total Population growth or decline : DR1 $1+141+1$

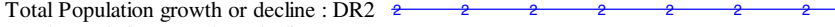

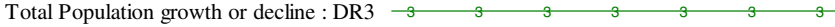

Total Population growth or decline : DR4 $\longrightarrow$ Total Population growh or decline : DR5

$$
\text { Total Population }
$$

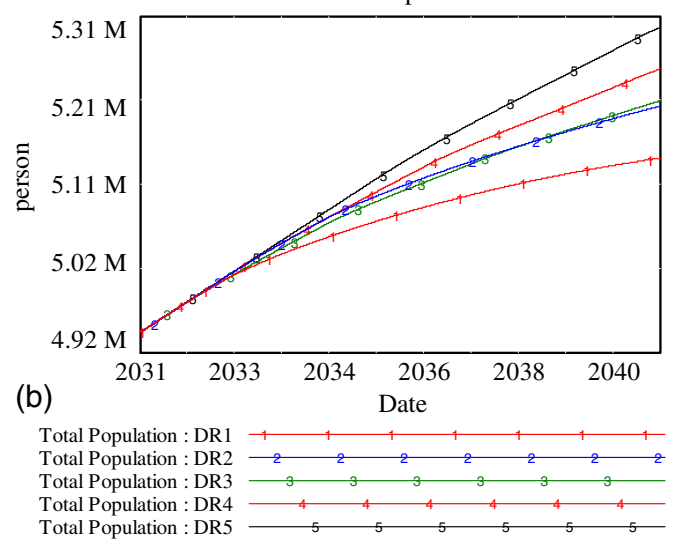

Fig. 9. Impact of drought scenarios $\operatorname{DR} x(x=1,2,3,4$, and 5) on the (a) growth rate; and (b) population.

region showed an upward trend in the temperature, precipitation, and streamflow (Neff et al. 2000), which means that the WMA water supply system is likely to have more water due to climate change in the future. Three out of four models for the Chesapeake Bay watershed predict an increase in mean annual precipitation and streamflow. However, in the western United States, the total annual precipitation is projected to decrease (EPA 2016).

On the basis of the ranges provided in Table 1, 990 climate change scenarios were constructed by applying 11 increments of $0.05^{\circ} \mathrm{C}$ for the temperature, 10 increments of $1 \%$ for the precipitation, and 9 increments of $1 \%$ for the streamflow. Climate change was imposed upon the system starting in the year 2031. In order to examine the impact of both climate change and drought on system reliability, we imposed a moderately severe drought in the year 2040 and performed all 990 climate change scenarios. Reliability $R_{v}$ was estimated for each climate change scenario and plotted on a surface and contour graph as a function of the precipitation and streamflow, keeping the temperature fixed at $\Delta \mathrm{T}=1.25^{\circ} \mathrm{C}$ (Fig. 10). The reliability of the system increased with an increase in the streamflow and precipitation. Although not shown in Fig. 10, the reliability of the system decreased as the temperature increased.

Table 4 presents the reliability of the system as the climate variables (temperature, precipitation, and streamflow) vary from low to mean to high values. The model projects that the WMA water supply system will become more reliable $\left(R_{v}=0.85\right)$ under a scenario in which the climate variables take their mean values. Under a scenario in which climate change is assumed to have no impact on climate variables and a moderately severe drought occurs in 2040, the WMA water supply and demand system reliability will be 0.82 . 

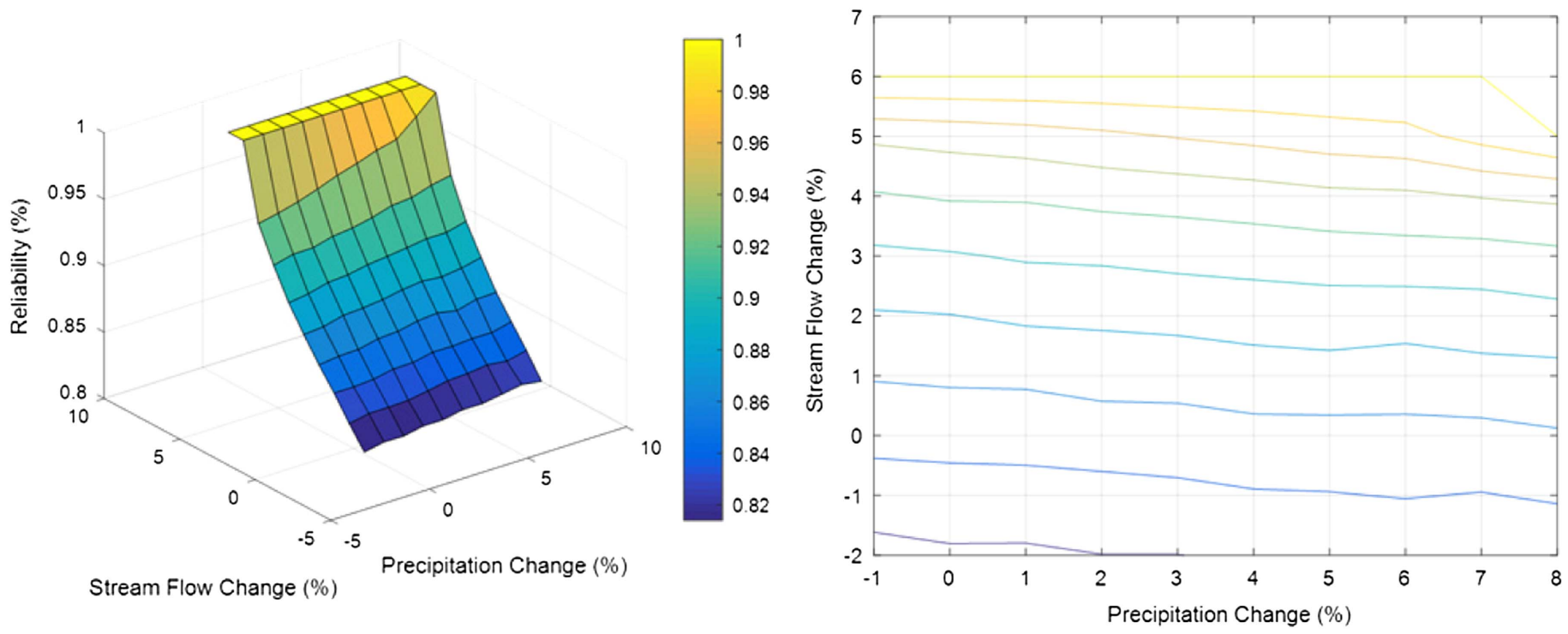

Fig. 10. System reliability under multiple climate change scenarios $\left(\mathrm{T}=1.25^{\circ} \mathrm{C}\right)$.

Table 4. System reliability under low, mean, and high climate change scenarios

\begin{tabular}{lcccc}
\hline $\begin{array}{l}\text { Climate } \\
\text { change } \\
\text { scenarios }\end{array}$ & $\begin{array}{c}\text { Change in } \\
\text { temperature } \\
\left({ }^{\circ} \mathrm{C}\right)\end{array}$ & $\begin{array}{c}\text { Change in } \\
\text { precipitation } \\
(\%)\end{array}$ & $\begin{array}{c}\text { Change in } \\
\text { streamflow } \\
(\%)\end{array}$ & Reliability \\
\hline Low & 1.5 & -1 & -2 & 0.78 \\
Mean & 1.25 & 4 & 2 & 0.85 \\
High & 1 & 8 & 6 & 1 \\
No change & & & & 0.82 \\
\hline
\end{tabular}

Finally, the simulation model projects that if climate variables move toward the lower end of their range, then the reliability will fall to 0.78 (Table 4).

If climate change specific to the Potomac River Basin came into effect by 2030 , it would impact water availability so that a 10 -year continuous moderately severe drought [Fig. 11(b)] would be reduced to a seven-year drought [Fig. 11(a)] for mean climate change conditions. This severe drought would completely disappear for climate change conditions at the higher end of their range, because climate change would cause both precipitation and streamflow to increase (Table 4)

\section{Policy Alternative Scenario Analysis}

The paper explores policies that water utilities can control, such as price and system losses. We tested two policy alternatives and examined their impact on the WMA water supply system. One alternative was to study the impact of the system losses, which is an important parameter in making planning-level estimates of future water demand. System losses are calculated by taking the difference between the amount of water produced by water suppliers and the amount of water billed to customers (ICPRB 2010)

System losses $(S L)$

$$
=\frac{\text { Total water produced }- \text { Total water billed to customers }}{\text { Total water billed to customers }}
$$

Generally, system losses tend to increase as water infrastructure ages. We assumed that this parameter was constant at $15 \%$ over the entire simulation period. For the purpose of analysis, this parameter
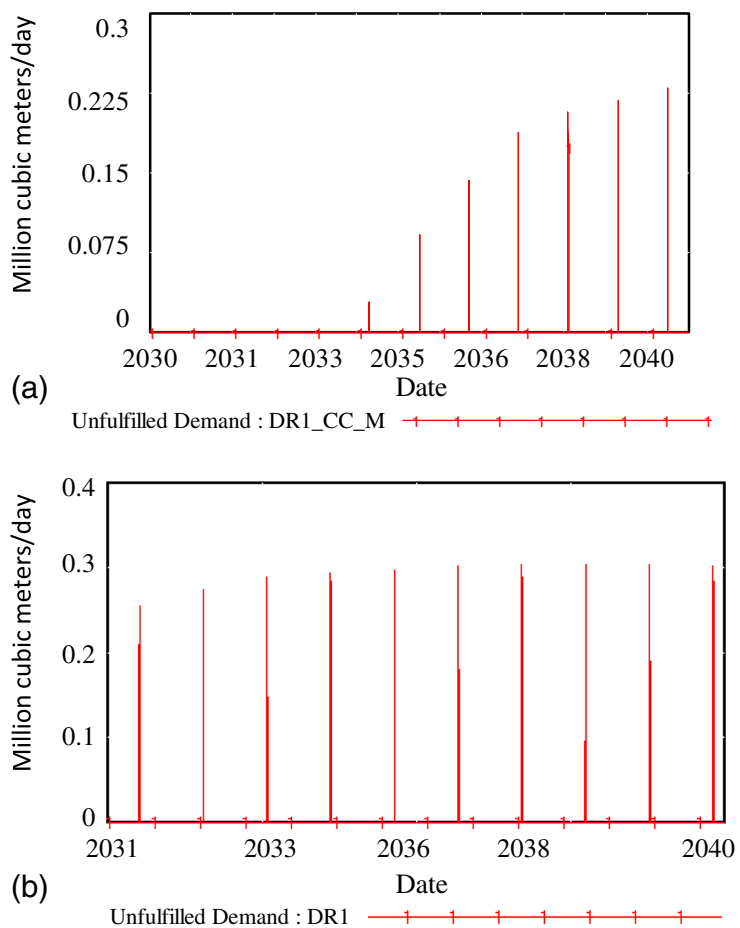

Fig. 11. Water availability: (a) drought with climate change; and (b) drought without climate change.

was allowed to vary in order to assess its impact on water restrictions. Price was another policy parameter that we varied to examine its impact on water availability. Price was one of the ways chosen to regulate demand because an increase in water price leads to a decrease in water demand. Water use is inversely related to water price (inferred from the parameter values provided in Table 4). Water price, unlike system losses, is not assumed constant over the simulation period. The water price for future years was projected on the basis of historical prices (DC Water 2015).

We simulated a total of 154 policy scenarios involving price and system losses for which we considered 11 values for water price that was increased by $100 \%$ in increments of $10 \%$ and 14 values 


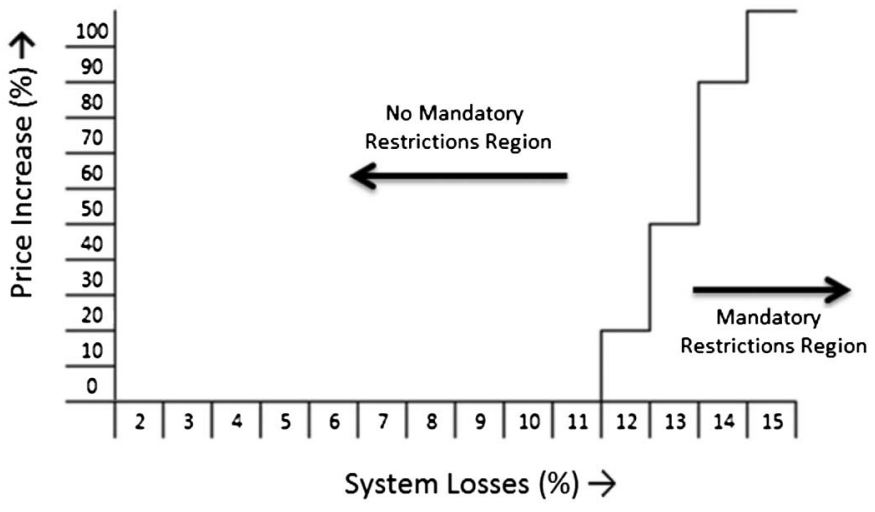

Fig. 12. Impact on system losses and price on restrictions (system under moderately severe drought in 2028).

for system losses that were reduced from 15 to $2 \%$ in increments of $1 \%$. Although, studies show that water losses increase over time (Sturm et al. 2015), the paper assumes water utilities will invest in capping system losses over time. Also, to examine whether the policy variables could make a difference in water availability, a moderately severe drought was imposed on the WMA water supply and demand system for the year 2025.

If there were no policy intervention (that is, no change to price and system losses), the system would experience the imposition of mandatory water use restrictions such as a ban on outside water use. It was observed that few policy intervention scenarios were able to reduce the severity of the restrictions. Fig. 12 shows that reducing the system losses is a more effective policy alternative than increasing the price. The left side of Fig. 12 shows combinations of system losses and price with which the region would not experience mandatory restrictions. Fig. 12 also shows that if the system losses were capped at $11 \%$, the region would not experience mandatory restrictions under a moderately severe drought in 2025. A mix of the two policies could be adopted to achieve the same results. For instance, if the system losses could not be reduced below $13 \%$, a $50 \%$ or greater increase in the base price would have the same effect on restrictions.

\section{Conclusions}

The WMA water supply system complexity makes it difficult for policy makers to assess the systemic and coalesced impact of droughts, climate change, and management policies. An interactive modeling approach that can involve multiple stakeholders and have an easy user interface along with strong dynamic modeling capabilities can be a useful approach for planners. The creation of multiple policy, climate, and drought scenarios assists planners to examine what-if scenarios as they look into the future. The accuracy of the scenarios is limited by their assumptions and therefore should be used for exploration rather than prediction.

For planning purposes, the system dynamics-based exploration presented in this study found that the WMA would be self-sufficient under normal conditions during the entire planning horizon but would be strained under moderately severe droughts. Because three out of four climate change scenarios for the Potomac River basin indicate an increasing trend in streamflow and precipitation, climate change is expected to positively impact water supply system reliability. But one of the four climate change scenarios projects a decrease in precipitation and streamflow, in which case the reliability would decrease. However, an increase in water resources brought about by climate change would give respite for only a few years. Our modeling scenarios indicate that under historical drought conditions, the leverage from climate change will be exhausted and the system may face water shortages within the planning horizon. Thus, planners should look for management strategies to counter the effect of the growing water demand fueled by the predicted $24 \%$ population growth in the WMA region. Regulating price and system losses can be very valuable tools to leverage, but these policy interventions require stakeholder participation (price regulation) and capital investments (reduction of distribution losses). Finally, system reliability can also be improved by increasing supply. Management policies regarding increasing the supplies have not been included in this study due to the uncertainty in the volume and timeline of the new supply sources being explored. These options can be explored in future studies.

\section{Acknowledgments}

This work benefited from the constructive feedback of several anonymous reviewers and the editorial team at the Journal. The authors gratefully acknowledge the input from these individuals. The US Department of Agriculture (USDA) prohibits discrimination in all its programs and activities on the basis of race, color, national origin, age, disability, and where applicable, sex, marital status, familial status, parental status, religion, sexual orientation, genetic information, political beliefs, reprisal, or because all or part of an individual's income is derived from any public assistance program. (Not all prohibited bases apply to all programs.) Persons with disabilities require alternative means for communication of program information (Braille, large print, audiotape, etc.) should contact USDA's TARGET Center at (202) 720-2600 (voice and TDD). To file a complaint of discrimination, write to USDA, Director, Office of Civil Rights, 1400 Independence Avenue, S.W., Washington, D.C. 20250-9410, or call (800) 795-3272 (voice) or (202) 720-6382 (TDD). USDA is an equal opportunity provider and employer.

\section{Supplemental Data}

The model and the specifics of all equations are available online in the ASCE Library (www.ascelibrary.org).

\section{References}

Ahmed, S. N., K. R. Bencala, and C. L. Schultz. 2011. Washington metropolitan area drought operations summary and lessons learned. Rep. No. 11-04. Rockville, MD: Interstate Commission on the Potomac River Basin.

Alcamo, J., and T. Henrichs. 2002. "Critical regions: A model-based estimation of world water resources sensitive to global changes." Aquat. Sci. Res. Across Boundaries 64 (4): 352-362. https://doi.org/10.1007 /PL00012591.

Arbués, F., R. Barberan, and I. Villanua. 2000. "Water price impact on residential water demand in the city of Zaragoza: A dynamic panel data approach." In Proc., 40th European Congress of the European Regional Studies Association. East Sussex, UK: Regional Studies Association.

Bencala, R. K., H. L. N. Moltz, and J. B. Palmer. 2013. Cooperative water supply operations for the Washington metropolitan area. ICPRB-13-4. Rockville, MD: Interstate Commission on the Potomac River Basin.

Bhatkoti, R. 2016. "Infrastructure performance and risk assessment under extreme weather and climate change conditions." Ph.D. dissertation, Virginia Tech. 
Chung, G., J. H. Kim, and T. W. Kim. 2008. "System dynamics modeling approach to water supply system." KSCE J. Civ. Eng. 12 (4): 275-280. https://doi.org/10.1007/s12205-008-0275-x.

Cohen, D., U. Shamir, and G. Sinai. 2004. "Sensitivity analysis of optimal operation of irrigation supply systems with water quality considerations." Irrig. Drain. Syst. 18 (3): 227-253. https://doi.org/10.1007 /s10795-004-9145-y.

Dandy, G., T. Nguyen, and C. Davies. 1997. "Estimating residential water demand in the presence of free allowances." Land Econ. 73 (1): 125-139. https://doi.org/10.2307/3147082.

Davies, E. G. R., and S. P. Simonovic. 2011. "Global water resources modeling with an integrated model of the social-economic-environmental system." Adv. Water Resour. 34 (6): 684-700. https://doi.org/10 .1016/j.advwatres.2011.02.010.

Dawadi, S., and S. Ahmad. 2013. "Evaluating the impact of demand-side management on water resources under changing climatic conditions and increasing population." J. Environ. Manage. 114 (Jan): 261-275. https://doi.org/10.1016/j.jenvman.2012.10.015.

DC Water. 2015. "Rates and metering." Accessed January 2015. https:// www.dcwater.com/rates-and-metering.

Dogan, G. 2007. "Bootstrapping for confidence interval estimation and hypothesis testing for parameters of system dynamics models." Syst. Dyn. Rev. 23 (4): 415-436. https://doi.org/10.1002/sdr.362.

Dutta, A., H. Lee, and M. Yasai-Ardekani. 2014. "Digital systems and competitive responsiveness: The dynamics of IT business value." Inf. Manage. 51 (6): 762-773. https://doi.org/10.1016/j.im.2014.05.005.

Ejeta, M. Z., T. McGuckin, and L. W. Mays. 2004. "Market exchange impact on water supply planning with water quality." J. Water Resour. Plann. Manage. 130 (6): 439-449. https://doi.org/10.1061/(ASCE) 0733-9496(2004)130:6(439).

EPA. 2016. "Energy Policy Act (EPA) of 1992.” Accessed January, 2016. https://www3.epa.gov/climatechange/impacts/water.html.

Evan, G. R., and S. P. Davies. 2011. "Global water resources modeling with an integrated model." Adv. Water Resour. 34 (6): 684-700. https://doi .org/10.1016/j.advwatres.2011.02.010.

Hagen, E. R., and J. Kiang. 2002. Drought operations and lessons learned Washington metropolitan area. Rep. No. 03-6. Rockville, MD: Interstate Commission on the Potomac River Basin.

Hagen, E. R., and R. C. Steiner. 1998. Occoquan reservoir watershed: "Natural" daily inflow development. ICPRB Rep. 98-3. Rockville, MD: Interstate Commission on the Potomac River Basin.

Hagen, E. R., and R. C. Steiner. 1999. Little Seneca reservoir "natural" daily inflow development. ICPRB Rep. 99-3. Rockville, MD: Interstate Commission on the Potomac River Basin.

Hanasaki, N., et al. 2013a. "A global water scarcity assessment under Shared Socio-economic pathways-Part 1: Water use." Hydrol. Earth Syst. Sci. 17 (7): 2375-2391. https://doi.org/10.5194/hess-17-2375-2013.

Hanasaki, N., et al. 2013b. "A global water scarcity assessment under shared socio-economic pathways-Part 2: Water availability and scarcity." Hydrol. Earth Syst. Sci. 17 (7): 2393-2413. https://doi.org/10 .5194/hess-17-2393-2013.

Hassanzadeh, E., A. Elshorbagy, H. Wheater, and P. Gober. 2014. "Managing water in complex systems: An integrated water resources model for Saskatchewan, Canada." Environ. Modell. Software 58 (Aug): 12-26. https://doi.org/10.1016/j.envsoft.2014.03.015.

Hejazi, M., et al. 2014. "Long-term global water projections using six socioeconomic scenarios in an integrated assessment modeling framework." Technol. Forecasting Social Change 81 (Jan): 205-226. https:// doi.org/10.1016/j.techfore.2013.05.006.

Honda, T., N. Hagura, T. Yoshioka, and H. Imamizu. 2013. "Imposed visual feedback delay of an action changes mass perception based on the sensory prediction error." Front. Psychol. 4 (Oct): 760 https://doi.org/10 .3389/fpsyg.2013.00760.

Huang, G. H., and D. P. Loucks. 2000. "An inexact two-stage stochastic programming model for water resources model for water resources management under uncertainty." Civ. Eng. Environ. Syst. 17 (2): 95-118. https://doi.org/10.1080/02630250008970277.

ICPRB (Interstate Commission on the Potomac River Basin). 2010. 2010 Washington metropolitan area water supply reliability study. Rockville, MD: ICPRB.
ICPRB (Interstate Commission on the Potomac River Basin). 2013. 2010 Washington metropolitan area water supply reliability study. Part 2: Potential impacts of climate change. Rockville, MD: ICPRB.

IPCC (Intergovernmental Panel on Climate Change). 2000. Summary for policymakers. A special report of Working Group III of the Intergovernmental Panel on Climate Change. Cambridge, UK: Cambridge University Press.

IPCC (Intergovernmental Panel on Climate Change). 2007. Summary for policymakers. In Climate Change 2007: The Physical Science Basis. Contribution of Working Group I to the Fourth Assessment Report of the Intergovernmental Panel on Climate Change. Cambridge, UK: Cambridge University Press.

Juhn, J., W. G. Ha, and N. H. Choi. 1999. A system dynamics analysis of electronic commerce. Boston: System Dynamics Society.

Kiang, J. E., and E. R. Hagen. 2003. 2002 Drought operations and lessons learned Washington metropolitan area. Rep. No. 03-6. Rockville, MD: Interstate Commission on the Potomac River Basin.

Kojiri, T., T. Hori, J. Nakatsuka, and T. S. Chong. 2008. "World continental modeling for water resources using system dynamics." Phys. Chem. Earth Parts A/B/C 33 (5): 304-311. https://doi.org/10.1016/j.pce .2008.02.005.

Langsdale, S., A. Beall, J. Carmichael, S. Cohen, and C. Forster. 2007. "An exploration of water resources futures under climate change using system dynamics modeling." Integr. Assess. J. Bridging Sci. Policy 7 (1): 51-79.

LeDuc, D., and S. Wilson. 1999. "Outside water use restricted in Md." Washington Post. Accessed May 2015. http://www.washingtonpost .com/wp-srv/local/daily/aug99/restrict5.htm.

Madani, K., and M. A. Mariño. 2009. "System dynamics analysis for managing Iran's Zayandeh-Rud River Basin." Water Resour. Manage. 23 (11): 2163-2187. https://doi.org/10.1007/s11269-008-9376-z.

McMahon, T. A., T. A. Adeloye, and S. J. Zhou. 2006. "Understanding performance measures of reservoirs." J. Hydrol. 324 (1-4): 359-382. https://doi.org/10.1016/j.jhydrol.2005.09.030.

Meadows, D. H. 2008. Thinking in systems: A primer. Hartford, VT: Chelsea Green.

Meadows, D. H., D. L. Meadows, J. Randers, and W. W. Behrens III. 1972. Limits to growth, 160. New York: Universe Books Publishers.

Meehl, G. A., et al. 2007. "Global climate projections, in climate change 2007: The physical science basis." In Contribution of working group I to the fourth assessment report of the intergovernmental panel on climate change, edited by S. Solomon, et al. Cambridge, UK: Cambridge University Press.

Mehmet, S., and H. Yasarcan. 2015. Block diagrams of generic system dynamics models. Boston: System Dynamics Society.

Mirchi, A. 2013. "System dynamics modeling as a quantitative-qualitative framework for sustainable water resources management: Insights for water quality policy in the great lakes region." Ph.D. dissertation, Michigan Technological Univ.

MWCOG (Metropolitan Washington Council of Governments). 2009. Round 7.2 cooperative forecasting: Employment, population, and household forecasts to 2030 by traffic analysis zone. Washington, DC: MWCOG.

Najjar, R., L. Patterson, and S. Graham. 2009. "Climate simulations of major estuarine watersheds in the Mid-Atlantic region of the US." Clim. Change 95 (1-2): 139-168. https://doi.org/10.1007/s10584 -008-9521-y.

Neff, R., H. J. Chang, C. G. Knight, R. G. Najjar, B. Yarnal, and A. Walker. 2000. "Impact of climate variation and change on mid-Atlantic region hydrology and water resources." Clim. Res. 14 (3): 207-218. https://doi .org/10.3354/cr014207.

Ocanas, G., and L. W. Mays. 1981. "A model for water reuse planning." Water Resour. Res. 17 (1): 25-32. https://doi.org/10.1029 /WR017i001p00025.

Palmer, R. N., J. A. Smith, J. L. Cohon, and C. S. ReVelle. 1982. "Reservoir management in the Potomac River basin." J. Water Resour. Plann. Manage. 108 (1): 47-66.

Palmer, R. N., J. R. Wright, J. A. Smith, J. L. Cohon, and C. S. ReVelle. 1979. Vol. 1 of Policy analysis of reservoir operations in the Potomac 
river basin: Executive Summary. Technical Rep. No. 59. College Park, MD: Univ. of Maryland.

Qaiser, K., S. Ahmad, W. Johnson, and J. R. Batista. 2013. "Evaluating water conservation and reuse policies using a dynamic water balance model." Environ. Manage. 51 (2): 449-458. https://doi.org/10.1007 /s00267-012-9965-8.

Rogers, P. 2014. "California drought: Past dry periods have lasted more than 200 years, scientists say." Accessed February, 2016. http://www .mercurynews.com/.

Sabounchi, N. S., K. Triantis, S. Sarangi, and S. Liu. 2014. "Dynamic simulation modeling and policy analysis of an area-based congestion pricing scheme for a transportation socioeconomic system." Transp. Res. Part A Policy Pract. 59 (Jan): 357-383. https://doi.org/10.1016/j .tra.2013.11.007.

Saysel, A. K., Y. Barlas, and O. Yenigun. 2000. "Environmental sustainability in an agriculture development project: A system dynamics approach.” J. Environ. Manage. 64 (3): 247-260. https://doi.org/10 $.1006 /$ jema.2001.0488.

Schleich, J., and T. Hillenbrand. 2009. "Determinants of residential water demand in Germany." Ecol. Econ. 68 (6): 1756-1769. https://doi.org/10 .1016/j.ecolecon.2008.11.012.

Sheer, D. P. 1977. A perspective on the Washington metropolitan area water supply problem. ICPRB M-6. Rockville, MD: Interstate Commission on the Potomac River Basin.

Stagge, J. H., and G. E. Moglen. 2014. "Evolutionary algorithm optimization of a multireservoir system with long lag times." J. Hydrol. Eng. 19 (9): 05014011. https://doi.org/10.1061/(ASCE)HE.1943-5584.0000972.

Stave, K. 2003. "A system dynamics model to facilitate public understanding of water management options in Las Vegas, Nevada." J. Environ. Manage. 67 (4): 303-313. https://doi.org/10.1016/S0301-4797(02) 00205-0.

Sterman, J. D. 2000. Business dynamics: Systems thinking and modeling for a complex world. New York: McGraw-Hill.

Sturm, R., K. Gasner, and L. Andrews. 2015. Water audits in the United States: A review of water losses and data validity. Rep. No. 4372b. Denver: Water Research Foundation.

Sušnik, J., L. S. Vamvakeridou-Lyroudia, D. A. Savić, and Z. Kapelan. 2012. "Integrated system dynamics modelling for water scarcity assessment: Case study of the Kairouan region." Sci. Total Environ. 440 (2012): 290-306. https://doi.org/10.1016/j.scitotenv.2012.05.085.

USACE. 1997. Master manual for reservoir regulation, north branch Potomac River basin, appendix-A, Jennings Randolph Lake, West Virginia and Maryland. Baltimore: USACE.
USGS (US Geological Survey). 2015. "USGS current conditions for Maryland." Accessed January 2015. https://waterdata.usgs.gov/md/nwis /current/?type $=$ flow.

Van Dyne, L. 2007. "Water, water...” Accessed January, 2016. http://www .washingtonian.com/.

Van Emmerik, T. H. M., Z. Li, M. Sivapalan, S. Pande, J. Kandasamy, H. H. G. Savenije, A. Chanan, and S. Vigneswaran. 2014. "Socio-hydrologic modeling to understand and mediate the competition for water between agriculture development and environmental health: Murrumbidgee River basin, Australia." Hydrol. Earth Syst. Sci. 18 (10): 4239-4259. https://doi.org/10.5194/hess-18-4239-2014.

Van Oel, P. R., M. S. Krol, A. Y. Hoekstra, and R. R. Taddei. 2010. "Feedback mechanisms between water availability and water use in a semiarid river basin: A spatially explicit multi-agent simulation approach." Environ. Modell. Software 25 (4): 433-443. https://doi.org/10.1016/j .envsoft.2009.10.018.

Vensim. 2010. Vensim reference manual. Boston: VENTANA Systems, Inc.

Vickers, A. 1993. "The energy policy act: Assessing its impact on utilities." Am. Water Works Assoc. J. 85 (8): 56-62. https://doi.org/10.1002/j .1551-8833.1993.tb06041.x.

Wada, Y., L. P. van Beek, C. M. van Kempen, J. W. Reckman, S. Vasak, and M. F. Bierkens. 2010. "Global depletion of groundwater resources." Geophys. Res. Lett. 37 (20): 1-15. https://doi.org/10.1029 /2010GL044571.

Wang, K., and E. G. R. Davies. 2015. "A water resources simulation gaming model for the Invitational Drought Tournament." J. Environ. Manage. 160 (Sep): 167-183. https://doi.org/10.1016/j.jenvman.2015.06.007.

Williams, M. 1985. "Estimating urban residential water demand for water under alternative price measures." J. Urban Econ. 18 (2): 213-225. https://doi.org/10.1016/0094-1190(85)90018-X.

Wolock, D. M., and G. J. McCabe. 1999. "Estimates of runoff using waterbalance and atmospheric general circulation models." J. Am. Water Res. Assoc. 35 (6): 1341-1350. https://doi.org/10.1111/j.1752-1688.1999 .tb04219.x.

Wright, S. E. 1975. "Public responses to the energy shortage: An examination of social class variables." Retrospective theses and dissertations, Iowa State Univ.

WWF (World Water Forum). 2003. 3rd world water forum. Kyoto, Japan: WWF.

Yang, J., K. Lei, S. Khu, and W. Meng. 2015. "Assessment of water resources carrying capacity for sustainable development based on a system dynamics model: A case study of Tieling City, China." Water Resour. Manage. 29 (3): 885-899. https://doi.org/10.1007/s11269-014 -0849-y. 